\title{
Childhood obesity - Are we dealing with it appropriately?
}

\author{
Sathiadas $M G^{1}$
}

\section{Summary}

Obesity in children is on the rise and many countries have taken initial steps to prevent this epidemic. According to the theory of epigenetics the risk of obesity can be passed from one generation to the next, because of behavioural and/ or biological factors. Over the last years there has been more interest to explain the trans-generational diseases with the theory of epigenetics. Identifying an underlying cause for obesity is important but majority of the time it is the change in lifestyle.

Early diagnosis and the metabolic derangements associated with obesity have to be detected in a timely manner. The body fat mass is a better predictor of the metabolic derangement when compared to the BMI. Measurement of BMI is practical and cost effective in our set up.

Clinicians are encouraged to screen all children from 6 to 18 years old for obesity by making BMI measurements part of usual care. Physicians should also be talking with parents, many of whom do not realize when a child is obese and offer comprehensive, intensive behavioral interventions. The behavioural interventions are mainly life style modification and motivation.

\section{Introduction:}

The rise in childhood obesity has increased the awareness of this as a disease condition and need for intervention during the childhood period itself. Obesity is defined as a chronic, relapsing, multi-factorial, neurobehavioral disease, wherein an increase in body fat promotes adipose tissue dysfunction and abnormal fat mass physical forces, resulting in adverse metabolic, biomechanical, and psychosocial health consequences. (1)Childhood obesity is reaching alarming proportions in many countries and poses an urgent and serious challenge. The Sustainable Development Goals, set by the United Nations in 2015, identify prevention and control of noncommunicable diseases as core priorities. The prevalence of infant, childhood and adolescent obesity is rising around the world. Although rates may be plateauing in some settings, in absolute numbers there are more children who are overweight and obese in low- and middle-income countries than in high-income countries. (2)

Many children today are growing up in an obesogenic environment that encourages weight gain and obesity. Energy imbalance has resulted from the changes in food type, availability, affordability and marketing, as well as a decline in physical activity, with more time being spent on screen based and sedentary leisure activities. In addition to this, the academic workload to the children is high in schools with competitive examinations making the children seek additional classes out of school hours thereby reducing the time spent on outdoor activity.

\section{Epigenetics and Obesity}

The risk of obesity can be passed from one generation to the next, because of behavioural and/ or biological factors.Over the last years there has been more interest to explain the trans generational diseases with the theory of epigenetics. During the pre-pregnancy stages, maternal overweight and obesity may transmit altered genetic signalling causing an increased risk of overweight/obesity in offspring and an increased risk of other diseases like diabetes, cardiovascular diseases and cancer in offspring. During pregnancy,especially in the presence of gestational diabetes mellitus, unhealthy maternal nutrition in pregnant women who are overweight or obese may increase placental transfer of nutrients like glucose, lipids, fatty acids and amino acids which can alter foetal gene expression by covalent modification of DNA and chromatin, may have an impact on the stem cells and may alter the postnatal biologic process involved in substrate metabolism. These can increase the obesity and overweight in the offspring.(3)

Children who have suffered from undernutrition and were born with low birth weight or are short-for-age (stunted), are at far greater risk of developing overweight and obesity when faced with energy-dense diets and a sedentary lifestyle later in life. Attempts to deal with undernutrition and stunting during childhood may have led to the unintended consequences of obesity risk for these children. (2) 
Diagnosis of obesity and related metabolic derangements:

Most clinical and epidemiological work still relies on simple measures, such as body mass index (BMI) or skinfold thickness measurements. The majority of large-scale studies reporting increasing adiposity in children have used BMI as an index of body fatness, and BMI has been recommended as the best measurement for monitoring overweight in individuals in the paediatric population.(4)

The BMI is not a predictor of metabolic derangements associated with obesity when compared to BMIFat Mass (FM) which has been a better predictor of metabolic derangement. Measuring FM has been a difficult task and several studies in the adults have shown a correlation of FM and BMI hence still BMI is considered as a better measurement. (4) In children growth is generally described in terms of body weight, which is then normalized for height to give BMI. Various studies have described the development of BMI over time, but the body compartment changes that underlie the characteristic S-shaped curve with age remain obscure. (5)

A recent study done in the Northern part of the country also gives a clear distinction that FM is a better predictor of metabolic syndrome in children. The unpublished data of the preliminary study was presented at an international forum and it showed that Percentage Body Fat (PBF) measurements using bio impedance analysis picked overweight children better and correlated better with the incidence of metabolic syndrome when compared to BMI. (6)

Metabolic syndrome is defined as Waist Circumference (WC) $>90^{\text {th }}$ Centile for age UK standards(7) and two of the following i.e. FBS $>100 \mathrm{mg} / \mathrm{dl}$, High blood pressure $>+2$ SD for age for both diastole and systole BP, Either one component was considered as high (8), Hypertriglyceridemia $>150 \mathrm{mg} /$ $\mathrm{dl}(>1.7 \mathrm{mmol} / \mathrm{l})$ and HDL $<40 \mathrm{mg} / \mathrm{dl}(<1.03 \mathrm{mmol} / \mathrm{l})$. (7)
A recent study has shown the Sri Lankan cut off for PBF of more than $33.7 \%$ in girls and more than $28.6 \%$ in boys was associated with metabolic derangements. (9)

The BMI measurements has an advantages of generally correlates with metabolic and fat mass diseases in population studies, Commonly used, Reasonably reproducible, Low cost, Adequate measure for epidemiological studies and adequate screening metric for most patients.

The Disadvantages are, may not correlate with metabolic and fat mass diseases in an individual patient, does not account for muscle mass, BMI cut-off points do not distinguish between men and women, nor ethnic and racial considerations and should be used as part of the clinical evaluation, and not the sole measure of obesity for all patients (6)

The Percentage Body Fat has advantage that it being a more specific assessment of body fat (not muscle, etc.) and may be a reasonable longitudinal measure in patients adhering to resistance exercise training. The disadvantages are some measurement techniques are not always accurate, nor easily reproducible, electronic body fat measurements may be expensive and Cut-off points not validated to correlate to metabolic disease. (6)

\section{Evaluating a Child with Obesity:}

The measurement of weight for length in children belonging to 0-2 years and thereafter the BMI is currently accepted to screen the children for obesity. A BMI centile of $85-94^{\text {th }}$ is considered as overweight and $>95^{\text {th }}$ is considered as obesity.

The first step in evaluation is to see whether the child has an endogenous cause for the obesity which is seen only in a small percent of the children. (10) The key differentiating features of endogenous and idiopathic obesity is mentioned in table 1 . The causes of endogenous obesity, hormonal (table 2) and genetic syndromes and its associations (table3)are summarized.

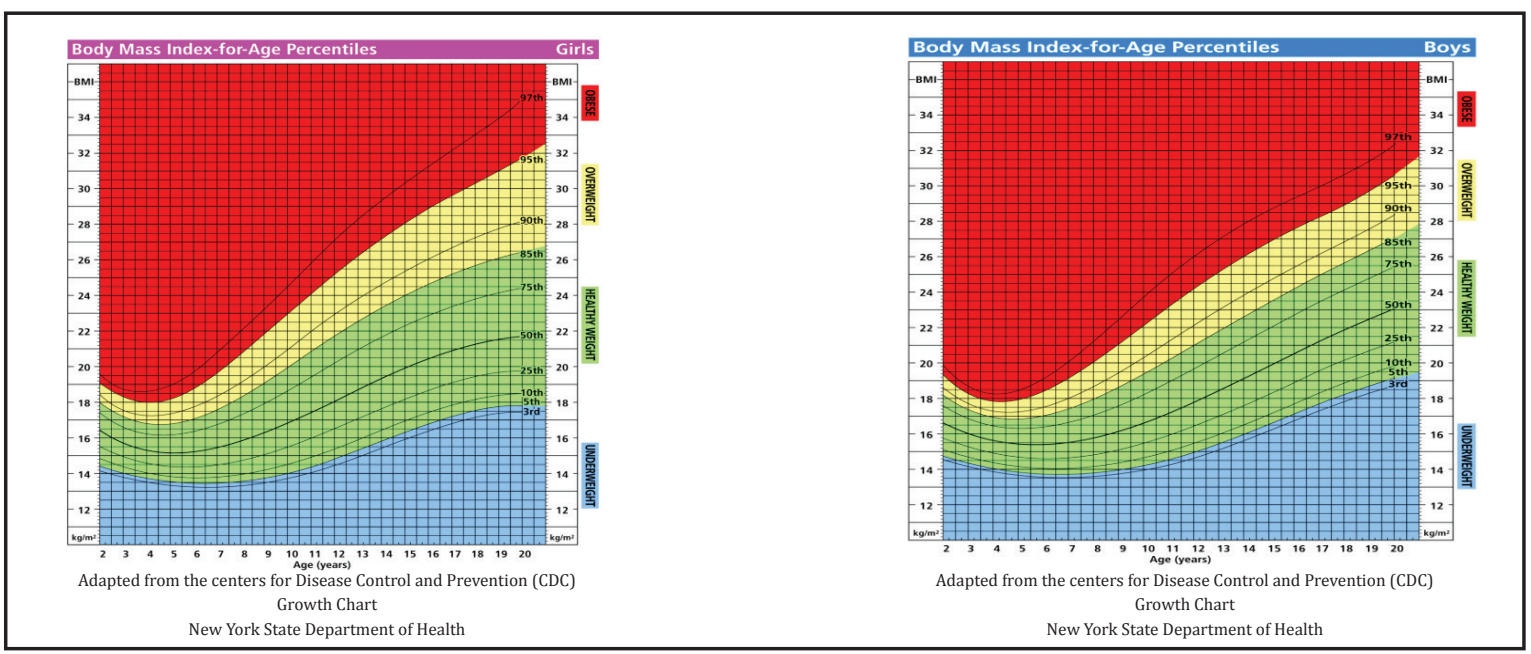


Table 1: Key features of endogenous and idiopathic obesity

\begin{tabular}{|l|l|l|}
\hline \multicolumn{1}{|c|}{ Features } & \multicolumn{1}{c|}{ Idiopathic } & \multicolumn{1}{c|}{ Endogenous } \\
\hline Incidence & $>90 \%$ & $<10 \%$ \\
\hline Height & Tall stature $\left(>50^{\text {th }}\right.$ centile $)$ & Short stature $\left(<5^{\text {th }}\right.$ centile $)$ \\
\hline Family history & Common & Uncommon \\
\hline Mental function & Normal & Reduced \\
\hline Bone age & Normal or mild advancement & Delayed \\
\hline Physical examination & Normal & Stigmata of disease present \\
\hline
\end{tabular}

\section{Endogenous causes of childhood obesity}

Table 2: Hormonal causes and features

\begin{tabular}{|l|l|}
\hline Hypothyroidism & Increased TSH, decreased thyroxine $\left(\mathrm{T}_{4}\right)$ levels \\
\hline Hypercortisolism & Abnormal dexamethasone suppression test; increased 24-hour free urinary cortisol level \\
\hline Primary hyperinsulinism & Increased plasma insulin, increased C-peptide levels \\
\hline Pseudohypoparathyroidism & Hypocalcaemia, hyperphosphatemia, increased PTH level \\
\hline Acquired hypothalamic & Presence of hypothalamic tumor, infection, syndrome trauma, vascular lesion \\
\hline
\end{tabular}

Table 3 : Genetic syndromes and associations:

\begin{tabular}{|l|l|}
\hline Prader-Willi & Obesity, insatiable appetite, mental retardation, hypogonadism, strabismus \\
\hline Laurence-Moon/Bardet-Biedl & $\begin{array}{l}\text { Obesity, mental retardation, pigmentary retinopathy, hypogonadism, spastic } \\
\text { paraplegia }\end{array}$ \\
\hline Alström & Obesity, retinitis pigmentosa, deafness, diabetes mellitus \\
\hline Börjeson-Forssman-Lehmann & Obesity, mental retardation, hypogonadism, hypo metabolism, epilepsy \\
\hline Cohen & Truncal obesity, mental retardation, hypotonia, hypogonadism \\
\hline Turner's & $\begin{array}{l}\text { Short stature, undifferentiated gonads, cardiac abnormalities, webbed neck, } \\
\text { obesity, 45, X genotype }\end{array}$ \\
\hline Familial lipodystrophy & $\begin{array}{l}\text { Muscular hypertrophy, acromegalic appearance, liver enlargement, acantho- } \\
\text { sisnigricans, insulin resistance, hypertriglyceridemia, mental retardation }\end{array}$ \\
\hline Beckwith-Wiedemann & Gigantism, exomphalos, macroglossia, visceromegaly \\
\hline Sotos' & $\begin{array}{l}\text { Cerebral gigantism, physical overgrowth, hypotonia, delayed motor and cog- } \\
\text { nitive development }\end{array}$ \\
\hline Weaver & Infant overgrowth syndrome, accelerated skeletal maturation, unusual facies \\
\hline
\end{tabular}

All obese children irrespective of the aetiology should be assessed for the associated morbidities. This includes an assessment of their metabolic derangements, weight related orthopedic problems, skin disorders and potential psychiatric sequelae. Screening for hypercholesterolemia should be undertaken for all obese children above two years of age. Blood pressure should be interpreted by measuring with the appropriate sized cuff and assessing using the age appropriate centile charts. While overt type 2 diabetes mellitus is rare in childhood, hyperinsulinemia and glucose intolerance are seen in morbidly obese children. (10) They carry excess weight hence assessment for tibialtorsion, bow legs, slipped capital femoral epiphysis and stress on the joints is needed. It is essential to address the problems like depression, poor self-esteem, negative self-image and withdrawal from peers. $(2,10)$

\section{Management:}

Overall management goal must be to improve body composition, develop healthy habits and lifestyle through to adulthood, improve health and quality of life, improve future adverse consequences and to improve body image and self-esteem.

The first steps in the management are identification of children with overweight or obesity done in primary health care services, counseling on consuming 5 or more portions of fruits and vegetables/day, $<2$ hours screen 
time, 1 hour of play or exercise, and no sugar-sweetened beverages. Motivational interviewing and family based counselling is initiated at the primary care level. Despite the preventive advice children who gain weight should be referred to a weight clinic or dietitian. If the child gains weight despite attending a weight clinic pharmacological or surgical options may be considered.

Parents and health professionals may be concerned that treating childhood obesity increases the risk of developing eating disorders. A Cochrane review found that reporting of harm was noticeably absent in lifestyle interventions. (11) This review reported an improvement in quality of life and self-esteem in children and young people undertaking weight management programmes. There is general agreement from systematic reviews that physical activity levels should be increased. The amount and intensity of activity required to affect childhood obesity is still unclear; however current recommendations for the general population of children and adolescents are an accumulation of at least 60 minutes of moderate activity per day. $(12,14)$ Expert opinion suggests that sedentary behaviours (screen time) should be reduced to no more than two hours per day or 14 hours over the week. (13)

Treatment programmes for managing childhood obesity should incorporate behaviour change components, be family based, involving at least one parent/carer and aim to change the whole family's lifestyle. Programmes should target decreasing overall dietary energy intake, increasing levels of physical activity and decreasing time spent in sedentary behaviours.

In most obese children (BMI $\geq 98$ th centile) weight maintenance is an acceptable treatment goal. For children with a BMI $\geq 99.6$ th centile a gradual weight loss to a maximum of $0.5-1.0 \mathrm{~kg}$ per month is acceptable. The benefits of weight maintenance (or modest weight loss in older children) should be demonstrated to families by charting weight over time on the BMI centile chart.

The management includes age appropriate changes in the physical activity, intake and behavior.

In an infant of 0-24 months the dietary measures include

Table 4 : Activity recommendation for older children

\begin{tabular}{|l|l|l|l|}
\hline \multicolumn{1}{|c|}{ Activity } & \multicolumn{1}{|c|}{ 5-9 years } & \multicolumn{1}{c|}{ 9-13 years } \\
\hline Aerobic & Running, Jumping & $\begin{array}{l}\text { Running, swimming, dancing, } \\
\text { bicycle riding }\end{array}$ & $\begin{array}{l}\text { Swimming, football, danc- } \\
\text { ing }\end{array}$ \\
\hline Bone building & Hopping, running, jumping & Basketball, tennis, running & Running, swimming \\
\hline Muscle strengthening & Tree climbing & $\begin{array}{l}\text { Push up, use resistance bands } \\
\text { free play, football }\end{array}$ & Use of free weights \\
\hline Active play & $\begin{array}{l}\text { Football, basketball, volley- } \\
\text { ball, tennis, track and field }\end{array}$ & $\begin{array}{l}\text { Yoga, Dancing, household } \\
\text { chores, running, }\end{array}$ \\
\hline
\end{tabular}

exclusive breast feeding upto 6 months, commencement of complimentary feeding at 6 months, avoid sugary sweetened beverages, avoid deserts and avoid fast food. In the age group of 2-4 years, the child should consume three main meals plus snack(s)3 servings of protein (1-3 oz)/day, 2-2.5 cups dairy/day, 3 servings non-starchy vegetables ( $3 / 4$ cup to 1.5 cups)/day and 1 cup/day of fruit. Dessert can be allowed only on special occasion, avoid fast food and sugary drinks. Age appropriate portion sizes are recommended and the child should be praised for trying new foods. In the 5-9 year age group three meals; $1-2$ snacks, 3 servings of protein/day, 2-3 servings of dairy/day, 1.5-2 servings of fruit/day and 4-5 servings non-starchy vegetables. Older children should also avoid sugary drinks. Children who are approaching adolescent age group can be allowed to leave food on the plate after eating. Force feeding and requesting them to finish should be avoided.

The behavior modification also varies with each age. Infant aged 0-24 months should be allowed on the floor/ play pen for play time. The 2-5 year old children should be encouraged active play almost constantly with minimal sedentary time and most importantly the screen time is zero in $<2$ years and $<1$ hour/day for 2-4 years. In the 5-9 year old group the screen time is $<1-2$ hours/day, routine sleep pattern, TV should not be allowed in the bed room, 11-14 hours of sleep and all meals should be consumed at the table. Parents should be role models and avoid controlling. Sleep study and adeno-tonsillectomy may be required if there is obstructive sleep apnoea. In older children peer groups become increasingly important, all meals at the table with family and encourage socialization. It is good to recommend meal and exercise tracking using electronic devices.

The activity in infants is mainly achieved in daily physical activity that is dedicated to exploring movement and environment. Active play is encouraged for short periods of time several times per day. Walking in the neighborhood, unorganized free play outdoors and walking through a park or zoo are good options. The 3-5 year old can engage in throwing/catching, running, swimming, tumbling and walking. Table 4 shows different types of exercises recommended for older children. 
If the lifestyle modifications do not work, pharmacotherapy may be tried. Orlistat should only be prescribed for severely obese adolescents (those with a BMI $\geq 99$.6th centile of the UK 1990 reference chart for age and sex) with comorbidities or those with very severe to extreme obesity (BMI $\geq 3.5$ SD above the mean of the UK 1990 reference chart for age and sex) attending a specialist clinic. There should be regular reviews throughout the period of use, including careful monitoring for side effects.

Bariatric surgery can be considered for post pubertal adolescents with very severe to extreme obesity (BMI $\geq 3.5$ SD above the mean on 1990 UK charts) and severe comorbidities.

\section{References:}

1. Suzanne E Cuda et al, Paediatric Obesity algorithm; Obesity Medicine Association. http://obesitymedicine. org/childhood-obesity/

2. WHO: guideline on management of childhood obesity. http://apps.who.int/iris/bitstream/10665/204176/1 /9789241510066_eng.pdf?ua=1\&ua=1

3. http://www.nature.com/ijo/journal/v39/n1/pdf/ ijo201434a.pdf

4. International Journal of Obesity (2000), A Hattori chart analysis of body mass index in infants and children, 24, 325-329

5. Fomon SJ, Haschke F, Ziegler EE, Nelson SE. Body composition of reference children from birth to age 10 years. Am J ClinNutr 1982; 35: 1169 \pm 1175 .

6. Sathiadas MG, Annieston A, Wickramasinghe VP, Screening for metabolic syndrome among school children in Jaffna district - a preliminary survey; Proceedings of the Sri Lanka College of Paediatricians $19^{\text {th }}$ annual scientific congress August 2017, p53

7. McCarthy HD ${ }^{1}$, Jarrett KV, Crawley HF, The development of waist circumference percentiles in British children aged 5.0-16.9 y EurJ ClinNutr. 2001 Oct;55(10):902

8. Jackson et al,Body mass index cut offs to define thinness in children and adolescents: international BMJ 2007; 335 doi:http://dx.doi.org/10.1136/ bmj.39238.399444.55. BMJ 2007;335:194Arch Dis Child 2007

9. Wickramasingheet al, Defining Obesity Using a Biological End Point in Sri Lankan Children. The Indian Journal of Pediatrics · July 2016, DOI: 10.1007/ s12098-016-2191-2

10. Evaluation and Treatment of Childhood Obesity REBECCA MORAN, M.D., Gilbert, Arizona Am Fam Physician. 1999 Feb 15;59(4):861-868.

11. Oude Luttikhuis H, Baur L, Jansen H, Shrewsbury VA, O'Malley C, Stolk RP, et al. Interventions for treating obesity in children (Cochrane Review). In: The Cochrane Library, Issue 1, 2009. London: Wiley.

12. Department of Health. At least five a week: Evidence on the impact of physical activity and its relationship to health.London: DoH; 2004. [cited 22 Dec 2009]. Available from url: http://www. dh.gov.uk/prod consum_dh/groups/dh_digitalassets/@dh/@en/ documents/digitalasset/dh_4080981.pdf

13. Barlow SE. Expert committee recommendations regarding the prevention, assessment, and treatment of child and adolescent overweight and obesity: summary report. Pediatrics 2007;120(Suppl 4):S164-92

14. The Scottish Government. Physical Activity Task Force. Let's Make Scotland More Active: A strategy for physical activity. Edinburgh: The Scottish Government; 2003. [cited 22 Dec 2009]. Available from url: http:// www.scotland.gov.uk/Publications/2003/02/1632 $4 / 17895$ 